\title{
PREDICTING THE IMPACT SIZE OF UNCERTAINTY EVENTS ON THE CONSTRUCTION COST OF HIGHWAY PROJECTS USING ANFIS
}

\author{
Alireza Moghayedi, and Abimbola Windapo \\ University of Cape Town, Cape Town, South Africa
}

\begin{abstract}
This study examines the use of Adaptive Neuro-Fuzzy Inference System (ANFIS) as a machine learning technique in the prediction of the impact size of uncertainty events on construction cost of highway projects and whether this technique is more accurate than the classical statistical methods. The rationale for the study stems from the availability of several techniques such as regression analysis and machine learning for developing predictive models of relationships of various variables in the construction industry. However, there has been limited research undertaken to compare the accuracy of the available techniques. The success or failure of prediction depends on the credibility of the prediction method. In this study, the predicted impact size of 76 uncertain events on the construction of highway projects using ANFIS as an intelligence machine learning method and Stepwise Regression Analysis (SRA) as a classical statistical method were compared to delineate the ability and accuracy of the ANFIS prediction technique. The comparison of calculated R-Value and two error tests for ANFIS and SRA show that the constructed ANFIS model has a higher performance than the SRA method in both fitness and reliability of the prediction model. Also, the performance comparison showed that ANFIS is a good tool for predicting the impact of uncertainty events on construction project cost. Based on these findings, the study concludes that the use of intelligent methods such as ANFIS will minimise the potential inconsistency of correlations in construction cost and time prediction. The model developed enables cost engineers to estimate the construction cost with a higher degree of accuracy.
\end{abstract}

Keywords: Accuracy, ANFIS, Construction Cost, Impact size, Predictability, SRA

\section{Introduction}

Providing accurate estimates of cost on construction projects is a difficult task because construction projects are subject to risks and uncertainties, especially in the planning phase of the project when sufficient data and information about the project is unavailable (Ökmen \& Öztaş, 2010). Typically, in the estimation of construction project resources, several variables are not known since uncertainties populate construction projects. According to El Khalek et al. (2016) various uncertainties are existing in construction projects that affect construction performance differently. A project is regarded as successful if it is completed on time, within budget and to the level of quality standards specified during the planning stage (Chan \& Chan, 2004).

Estimating construction cost at the early stage of project development represents a prediction provided by the cost engineer based on available information and data. Cost estimating is defined as that area of construction practice where the cost engineers' experience and judgment are utilised in the application of scientific principles and techniques to the problem of predicting and controlling cost of projects $(\mathrm{Ng} \&$ Zhang, 2008). The ANFIS model enables the ability to accurately predict the impact size of uncertainty events on construction cost which has always been one of the most critical challenges of cost engineers (Antunes \& Gonzalez, 2015). This advantage enables cost engineers to estimate the construction cost with higher performance by predicting the accurate impact amount of uncertainty events on construction cost using tailormade effect values table for individual projects (PMI, 2013). However, the success or failure of prediction depends on the credibility of the prediction method.

The intelligence machine learning techniques based on Fuzzy Inference System (FIS) is used in modelling the qualitative aspects without employing precise quantitative analyses, it provides standard practical methods for transformation into rule based as well as effective methods for turning Membership Functions (MF) for better performance index (Chai et al., 2009). ANFIS combines the strengths of Artificial Neural Network (ANN) with Fuzzy Inference Systems (FIS) to create an efficient method for analysing complex problems. ANFIS has the capability to handle nonlinearity, uncertainty, and complex problems which are involved in predicting the impact size of uncertainty events on construction cost (Jin, 2010).

ANFIS has been used in various fields of engineering. For instance, Ugur (2017) used ANFIS to estimate the costs of the residential building. While Fragiadakis et al. (2014) used ANFIS to assess the occupational risk in the shipbuilding industry; Ebrat and Ghodsi (2014) applied ANFIS to evaluate the risk in construction projects; Li et al. (2011) forecasted building energy consumption using hybrid ANFIS; GüNeri et al. (2011) used ANFIS to overcome supplier selection problem in construction projects; Shahhosseini and Sebt (2011) used ANFIS to establish a fuzzy adaptive decision-making model for selection and assignment of human resources to construction projects based on 
competency; and Wang and Elhag (2008) developed an ANFIS based risk assessment model for bridge maintenance projects.

On the other hand, classical statistical methods such as regression analysis are quite common in predicting different variables in construction management. Regression analysis methods are relatively easy to implement, and the main advantage of these methods are that the relationship between the input variables and output variables is easy to comprehend. Stepwise Regression Analysis (SRA) is an extension of Multiple Regression Analysis. The SRA model is a mathematical model used in estimating the relationship between a dependent variable and independent variables with a strong mathematical background. SRA models have been used extensively in different areas of construction management. For instance, assessing the critical factors affecting cost performance of public construction projects (Sinesilassie et al., 2017); modelling the construction risk ratings and estimating contingencies in highway projects (Diab et al., 2017); identifying the success factors for public, private partnership projects (Yun et al., 2015); evaluating project risks (Ebrat \& Ghodsi, 2014); evaluating the risk factors leading to cost overrun in highway construction projects (Creedy et al., 2010); analysing the risk perception of buildoperate-transfer road project participants (Thomas et al., 2003); developing models to forecast the actual construction cost and time (Skitmore \& Ng, 2003); and designing a multivariate analysis technique to rank project success factors (Chan et al., 2001).

The primary objective of this study is to evaluate and compare the performance of machine learning technique (ANFIS) with the classical statistical method (SRA) in the prediction of the impact size of uncertainty events and to determine a reliable and accurate prediction technique. The prediction technique involves developing a model, estimating the value and evaluating the performance (reliability and fitness) of predicted value to the real data. According to PMI (2013), the impact amount of uncertainty is a function of the impact size and effect value (See Equation 1).

${\text { Impact } \text { amount }_{i}=\text { Impact }_{\text {size }} \times} \times$ Effect value $_{i}$.

By predicting the accurate impact size of events on the cost of the project it is possible to estimate the exact impact amount of events on the construction cost of the project (PMI 2013).

However, there are limited researches undertaken using ANFIS in the field of construction management and limited studies have compared the accuracy of ANFIS as a technique for predicting the impact size of uncertainty events on construction cost to available classical prediction techniques such as SRA.
The novelty of this study is that it examines the predicted impact size of uncertainty events on the construction cost of highway projects using ANFIS as an intelligence method and SRA as a classical statistical method based on the standard impact matrix, and thereafter compares the ability and accuracy of the two prediction techniques. Therefore, this study shows the ability of ANFIS technique as an intelligence method in predicting the impact size of uncertainty events on the construction cost of highway projects on important step in cost estimation. Thereafter the study compares the reliability and accuracy of the ANFIS to the ability and performance of SRA as a classical prediction method. This approach is straightforward and provides the accurate impact size of uncertainty events on the construction cost of highway projects and a holistic overview of the advantages of the ANFIS to the classical prediction methods.

\section{Uncertainty Events on Highway Projects}

Uncertainty means an unknown phenomenon that is associated to the location and is project specific and has no root causes that can be generalised (Ramanathan et al., 2012). Therefore, there is an obvious need to effectively anticipate, identify and classify the uncertainty events on different locations and projects to assess their influence on the objectives of construction projects. Moghayedi and Windapo (2018) identified 76 uncertainty events as affecting the construction of South African highway projects under seven major groups namely Economical, Environmental, Financial, Legal, Political, Social and Technical as illustrated in Figure 1. It can be seen from Figure 1that more than half (41) of the uncertainty events are attributed to Technical factors.

The 76 uncertainty events identified by Moghayedi and Windapo (2018) was used in the current study to evaluate the performance of proposed techniques for predicting the impact size uncertainty events on construction cost of highway projects.

\section{Methodology}

The hierarchy structure of the model developed for predicting the impact size of uncertainty events consists of four main steps; 1 . determination of uncertainty event attributes; 2. data collection; 3 . developing the prediction models; and 4. comparison and recommendation. The process begins with a determination of criteria for uncertainty assessment. The magnitude influence of uncertainty can be assessed by two parameters, probability of occurrence and severity (ISO, 2009; PMI, 2013). To model, the impact of uncertainty events, the ISO 31000 (International Standard Organization) impact matrix was used (ISO, 2009). Figure 2 shows the probability of occurrence and severity as two input variables and relevant impact size as output of prediction models.

To model the impact of uncertainty events on 
construction cost and predict the impact size, the probability of occurrence and severity of the event were obtained from all 32 available professional project managers with a minimum of 20 years of work experience in South African highway construction projects recommended by The South African National Roads Agency SOC Ltd (SANRAL) using the fivepoint linguistic Likert scale questionnaires.

The ANFIS and SRA were used as intelligent and classical prediction models to predict and assess the impact size of 76 uncertainty events on construction cost. To evaluate the prediction performance of each techniques the two controlling indicators were adapted. The indicator to measure the reliability of techniques are Mean Absolute Percentage Error (MAPE) and Root Mean Square Error (RMSE). Regarding the fitness and efficiency of each technique, the model is indicated by the correlation coefficient (R). The ideal technique has RMSE and MAPE score of 0 and $\mathrm{R}$-value close to 1

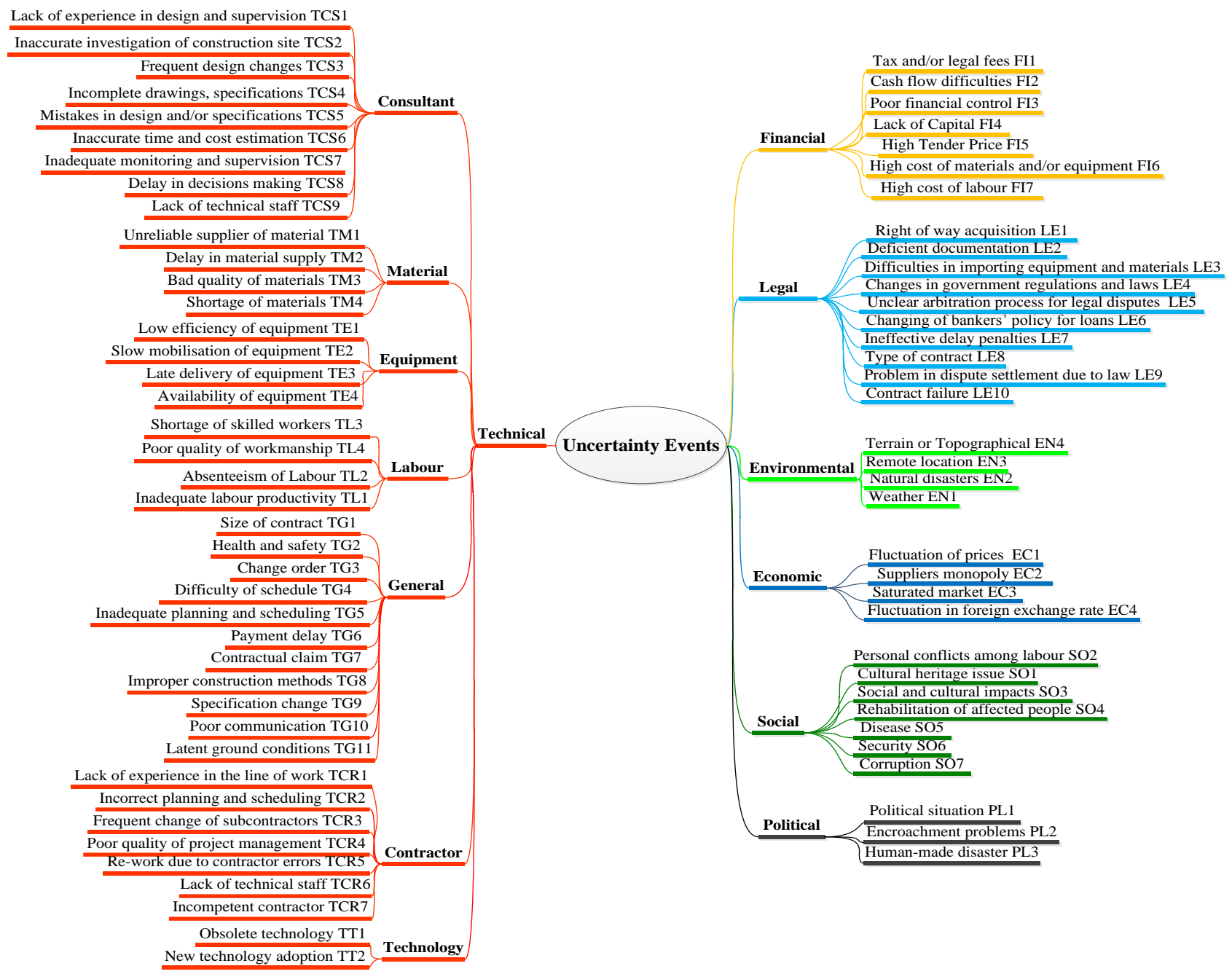

Source: Moghayedi and Windapo (2018)

Figure 1. Uncertainty event

\begin{tabular}{|c|c|c|c|c|c|c|}
\hline & \multicolumn{5}{|c|}{ Severity } \\
\hline & & Insignificant (1) & Minor (3) & Moderate (5) & Major (7) & Catastrophic (9) \\
\hline \multirow{5}{*}{ 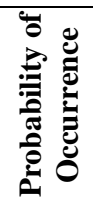 } & Rare $(0.1)$ & Minimal (1) & Minimal (1) & Low (2) & Low (2) & Moderate (3) \\
\hline & Unlikely $(0.3)$ & Minimal (1) & Low (2) & Moderate (3) & Moderate (3) & High (4) \\
\hline & Possible (0.5) & Low (2) & Moderate (3) & Moderate (3) & High (4) & High (4) \\
\hline & Likely $(0.7)$ & Low (2) & Moderate (3) & High (4) & High (4) & Extreme (5) \\
\hline & Almost Certain (0.9) & Moderate (3) & High (4) & High (4) & Extreme (5) & Extreme (5) \\
\hline
\end{tabular}

Source: ISO (2009)

Figure 2: Probability of Occurrence of the Event and Severity 


\section{Adaptive Neuro-Fuzzy Inference System}

ANFIS refers to combinations of Artificial Neural Networks (ANN) and Fuzzy Inference System (FIS). Fuzzy modelling and ANN have been recognised as powerful tools that can facilitate the effective development of models and integrate information. These two tools were combined to achieve readability and learning ability at the same time. ANFIS, trained to develop fuzzy rules and determine Membership Functions (MF) for input and output variables of the system is an intelligent system which is able to estimate the variables and fuzzy rules intelligently and does not require a systematic method for design of fuzzy systems. Also, neural network fuzzy systems interpret the human knowledge and deduce it into a mathematical model (Negnevitsky, 2005). The NeuroFuzzy has two major categories: linguistic fuzzy modelling which is focused on interpretability
(Mamdani), and precise fuzzy modelling which is focused on accuracy (Takagi-Sugeno) (Lughofer, 2011). In this study, a first-order Takagi-Sugeno fuzzy inference system is employed to accurately assess the impact size of uncertainty events in construction cost of highway projects. In this inference system, the output of each rule is a linear combination of two input variables added by a linear term of "AND" logic. The final output is the weighted average of each rule's output. Figure 3 illustrates the Takagi-Sugeno ANFIS structure which was developed for this study. To model this ANFIS following 25 fuzzy rules "If-Then" are considered (See Equation 2).

$$
\text { If ( } P \text { is pi) AND (S is si) Then } f i=a i p+b i s+r i
$$

Where $P$ and $S$ are numerical inputs while pi and si are numerical variables. ai, bi and ri are parameters that determine the relation between input and output

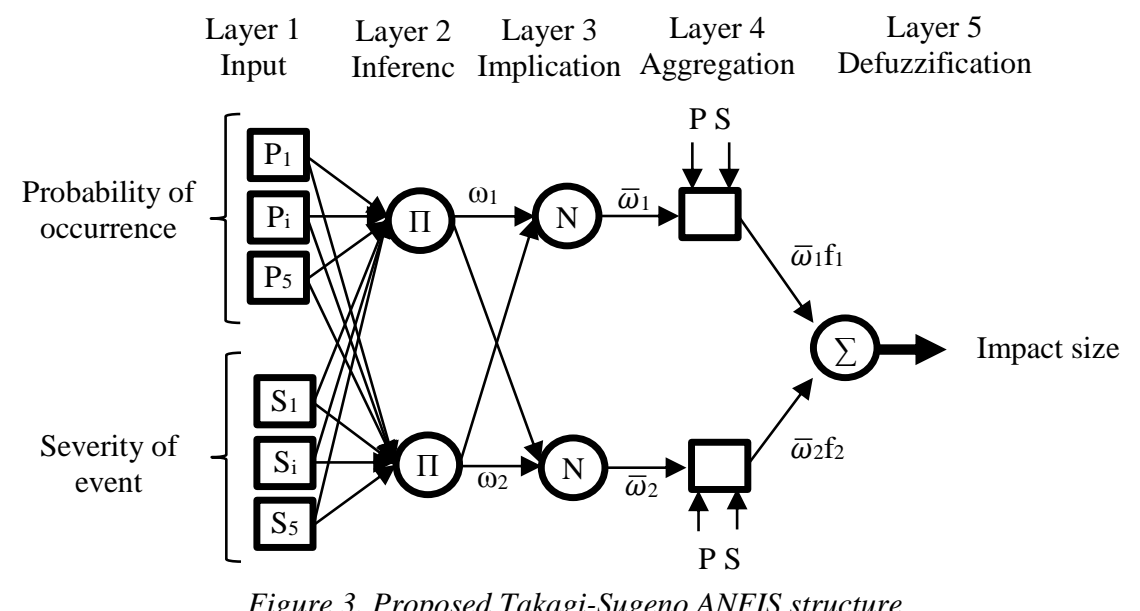

Figure 3. Proposed Takagi-Sugeno ANFIS structure

ANFIS is modelled in MATLAB to predict the impact size of uncertainty events. Eighty percent $(80 \%)$ of the data collected from the research participants was used for training of the FIS, while twenty percent (20\%) was used for checking and testing the neural network which set the system parameters. To evaluate the performance of 76 models developed by ANFIS (a model to fit each uncertainty event was developed), the RMSE, MAPE and R-Value of the predicted impact size of uncertainty events are calculated and the results are presented in Table 3 . The minimal error scores of RMSE $(\mathrm{e}<0.3)$ and MAPE $(\mathrm{e}<0.1)$ proved the high reliability of ANFIS models (Veerasamy et al., 2011). Furthermore, the extreme closeness of R-Values to 1 verified the excellent fitness $(r>0.9)$ of predicted impact sizes of all models to the real data $(20 \%$ of observed data) (Moore \& Kirkland, 2007).

\section{Stepwise Regression Analysis}

The impact size of uncertainty event as the dependent variable is a function of two independent variables namely probability of occurrence and severity of relative uncertainty (ISO, 2009) shown in Equation 3.

$$
\text { Uncertainty } \text { Impact }_{i}=a_{i} p+b_{i} s+r_{i}
$$

Where $p$ is probability of occurrence, $s$ is severity of event, ri is a constant value, ai and bi represent regression coefficient of independent variables

The linear regression analysis was used to generate correlations coefficients of the two independents variables (probability of occurrence and severity) of uncertainty events by using the SRA in the MATLAB. An SRA technique was selected due to the low correlation between the independents' variables and dependent variable as presented in Table 1. The general SRA model for predicting the impact size of uncertainty events has been developed based on the matrix impact in Figure 2. The SRA model test details are presented in Table 2.

Table 1. Correlation matrix among input and output variables

\begin{tabular}{lccc}
\hline & Probability & Severity & Impact \\
\hline Probability & 1 & & \\
Severity & 0 & 1 & \\
Impact & 0.685061 & 0.685061 & 1 \\
\hline
\end{tabular}


Table 2. Regression test details

\begin{tabular}{lcccc}
\hline \multicolumn{2}{c}{ Regression Statistics } & & & \\
\cline { 1 - 4 } Multiple R & 0.968822 & & & \\
R Squared & 0.93861607 & & & \\
Adjusted R Square & 0.93303571 & & & \\
Standard Error & 0.31622777 & & & \\
\cline { 1 - 4 } & Coefficients & Standard Error & T Stat & P-value \\
\hline Intercept & 0.18 & 0.170294 & 1.056996 & 0.030198 \\
Probability & 2.9 & 0.223607 & 12.96919 & $8.82 \mathrm{E}-12$ \\
Severity & 0.29 & 0.022361 & 12.96919 & $8.82 \mathrm{E}-12$ \\
\hline
\end{tabular}

The regression test revealed the correlation coefficient value of the model is close to 1 which verifies the close fitness of the estimated output model with real data (impact matrix). Also, the low value of $\mathrm{P}$-value $(<0.05)$ indicates the statistically significant relationship of each independent variable to the dependent variable of the model. The developed SRA model for general uncertainty impact size is outlined mathematically in Equation 3.

$$
\text { Impact Size }=0.18+2.9 \times p+0.29 \times s
$$

The similar process was repeated to generate the SRA uncertainty impact models for each event. To predict the impact size of uncertainty the optimum values of probability of occurrence and severity of events are identified using sensitivity analysis and incorporated into SRA models. The impact of uncertainty events on the construction cost of highway projects was predicted.

To evaluate the performance of SRA models' on predicting the impact size of uncertainty events the (RMSE), (MAPE) and R-Value of developed models were calculated, and the results are presented in Table 3. The small error scores of RMSE and MAPE proved the reliability of SRA developed models. However, the fitness of the predicted values to real data varies from 0.367 to 0.816 . Only three models have good fitness $(0.9>r>0.8)$, nine models have acceptable fitness $(0.8>r>0.7)$, and the other ten models have a low fitness $(r<0.7)$ to the real data.

Table 3: ANFIS and SRA predicted impact size of uncertainty on cost of project and performance evaluation

\begin{tabular}{|c|c|c|c|c|c|c|c|c|}
\hline \multirow[b]{2}{*}{ Event } & \multicolumn{4}{|c|}{ ANFIS } & \multicolumn{4}{|c|}{ RSA } \\
\hline & $\begin{array}{c}\text { Impact } \\
\text { Size }\end{array}$ & RMSE & MAPE & R Value & $\begin{array}{c}\text { Impact } \\
\text { Size }\end{array}$ & RMSE & MAPE & R Value \\
\hline EC1 & 4.02 & $6.05 \mathrm{E}-08$ & $1.35 \mathrm{E}-08$ & 1.000000000000000 & 4.16 & 0.213 & 0.0484 & 0.659 \\
\hline EC2 & 4.08 & $1.07 \mathrm{E}-07$ & $1.73 \mathrm{E}-08$ & 0.999999999999999 & 3.94 & 0.246 & 0.0547 & 0.647 \\
\hline EC3 & 2.98 & $6.88 \mathrm{E}-08$ & $2.14 \mathrm{E}-08$ & 0.999999999999999 & 2.88 & 0.268 & 0.0857 & 0.506 \\
\hline EC4 & 3.88 & $1.27 \mathrm{E}-07$ & $2.06 \mathrm{E}-08$ & 0.999999999999999 & 3.69 & 0.247 & 0.0597 & 0.582 \\
\hline EN1 & 3.03 & $2.53 \mathrm{E}-07$ & $6.02 \mathrm{E}-08$ & 0.999999999999994 & 3.06 & 0.301 & 0.0943 & 0.649 \\
\hline EN2 & 3.84 & $1.39 \mathrm{E}-08$ & $2.94 \mathrm{E}-09$ & 1.000000000000000 & 3.84 & 0.251 & 0.062 & 0.665 \\
\hline EN3 & 4.21 & $3.36 \mathrm{E}-08$ & $7.08 \mathrm{E}-09$ & 1.000000000000000 & 4.09 & 0.228 & 0.0449 & 0.444 \\
\hline EN4 & 3.52 & $8.03 \mathrm{E}-08$ & $1.62 \mathrm{E}-08$ & 0.999999999999999 & 3.5 & 0.222 & 0.0513 & 0.821 \\
\hline FI1 & 3.22 & $2.16 \mathrm{E}-08$ & $6.59 \mathrm{E}-09$ & 1.000000000000000 & 3.13 & 0.253 & 0.0725 & 0.62 \\
\hline FI2 & 3.52 & $4.58 \mathrm{E}-08$ & $1.05 \mathrm{E}-08$ & 1.000000000000000 & 3.5 & 0.254 & 0.0666 & 0.766 \\
\hline FI3 & 3.13 & $7.55 \mathrm{E}-08$ & $1.43 \mathrm{E}-08$ & 1.000000000000000 & 3.5 & 0.249 & 0.0749 & 0.638 \\
\hline FI4 & 3.48 & $4.34 \mathrm{E}-08$ & $1.03 \mathrm{E}-08$ & 1.000000000000000 & 3.47 & 0.241 & 0.0595 & 0.789 \\
\hline FI5 & 3.75 & $2.65 \mathrm{E}-08$ & $6.07 \mathrm{E}-09$ & 1.000000000000000 & 3.75 & 0.249 & 0.0623 & 0.739 \\
\hline FI6 & 3.8 & $2.41 \mathrm{E}-08$ & $5.99 \mathrm{E}-09$ & 1.000000000000000 & 3.78 & 0.251 & 0.0613 & 0.785 \\
\hline FI7 & 3.65 & $2.41 \mathrm{E}-08$ & $5.69 \mathrm{E}-09$ & 1.000000000000000 & 3.63 & 0.233 & 0.0535 & 0.799 \\
\hline LE1 & 3.49 & $6.91 \mathrm{E}-08$ & $1.49 \mathrm{E}-08$ & 1.000000000000000 & 3.44 & 0.203 & 0.0472 & 0.851 \\
\hline LE10 & 3.3 & $6.85 \mathrm{E}-08$ & $1.06 \mathrm{E}-08$ & 1.000000000000000 & 3.31 & 0.249 & 0.0535 & 0.856 \\
\hline LE2 & 3.01 & $7.90 \mathrm{E}-08$ & $2.45 \mathrm{E}-08$ & 0.999999999999999 & 2.91 & 0.238 & 0.0607 & 0.801 \\
\hline LE3 & 1.7 & $1.20 \mathrm{E}-07$ & $4.82 \mathrm{E}-08$ & 0.999999999999996 & 1.75 & 0.168 & 0.07 & 0.954 \\
\hline LE4 & 3.19 & $7.37 \mathrm{E}-08$ & $1.42 \mathrm{E}-08$ & 0.999999999999999 & 3.09 & 0.243 & 0.0696 & 0.559 \\
\hline LE5 & 2.92 & $1.04 \mathrm{E}-07$ & $3.05 \mathrm{E}-08$ & 0.999999999999999 & 2.78 & 0.321 & 0.1133 & 0.664 \\
\hline LE6 & 3.15 & $2.49 \mathrm{E}-08$ & $6.99 \mathrm{E}-09$ & 1.000000000000000 & 3.28 & 0.278 & 0.0818 & 0.773 \\
\hline LE7 & 2.81 & $2.05 \mathrm{E}-07$ & $4.97 \mathrm{E}-08$ & 0.999999999999995 & 2.72 & 0.28 & 0.0989 & 0.76 \\
\hline
\end{tabular}




\begin{tabular}{|c|c|c|c|c|c|c|c|c|}
\hline LE8 & 2.98 & $9.11 \mathrm{E}-08$ & 2.47E-08 & 0.9999999999999999 & 3 & 0.244 & 0.072 & 0.644 \\
\hline LE9 & 3.29 & $5.77 \mathrm{E}-08$ & $1.40 \mathrm{E}-08$ & 1.000000000000000 & 3.19 & 0.331 & 0.0959 & 0.78 \\
\hline PL1 & 3.77 & $8.27 \mathrm{E}-08$ & $1.33 \mathrm{E}-08$ & 0.999999999999999 & 3.59 & 0.251 & 0.0633 & 0.718 \\
\hline PL2 & 3.21 & $5.84 \mathrm{E}-08$ & $1.66 \mathrm{E}-08$ & 1.000000000000000 & 3 & 0.268 & 0.0761 & 0.78 \\
\hline PL3 & 4.27 & $3.09 \mathrm{E}-08$ & $5.91 \mathrm{E}-09$ & 1.000000000000000 & 4.06 & 0.236 & 0.0502 & 0.803 \\
\hline SO1 & 2.73 & $2.20 \mathrm{E}-07$ & $5.87 \mathrm{E}-08$ & 0.999999999999994 & 2.78 & 0.269 & 0.0868 & 0.694 \\
\hline $\mathrm{SO} 2$ & 2.56 & $1.14 \mathrm{E}-07$ & $4.53 \mathrm{E}-08$ & 0.999999999999998 & 2.47 & 0.244 & 0.0668 & 0.784 \\
\hline $\mathrm{SO} 3$ & 3.72 & $5.31 \mathrm{E}-08$ & $1.40 \mathrm{E}-08$ & 1.000000000000000 & 3.69 & 0.238 & 0.0554 & 0.782 \\
\hline $\mathrm{SO} 4$ & 3.65 & $4.66 \mathrm{E}-08$ & $1.17 \mathrm{E}-08$ & 1.000000000000000 & 3.53 & 0.243 & 0.0618 & 0.782 \\
\hline SO5 & 4.11 & $3.59 \mathrm{E}-08$ & $7.38 \mathrm{E}-09$ & 1.000000000000000 & 4.03 & 0.193 & 0.0337 & 0.816 \\
\hline SO6 & 3.82 & $5.06 \mathrm{E}-08$ & $1.26 \mathrm{E}-08$ & 1.000000000000000 & 3.78 & 0.232 & 0.0539 & 0.739 \\
\hline SO7 & 4.17 & $7.54 \mathrm{E}-08$ & $7.99 \mathrm{E}-09$ & 1.000000000000000 & 4.09 & 0.252 & 0.0559 & 0.61 \\
\hline TCR1 & 2.98 & $5.54 \mathrm{E}-08$ & $1.66 \mathrm{E}-08$ & 1.000000000000000 & 2.81 & 0.166 & 0.0333 & 0.884 \\
\hline TCR2 & 3.22 & $4.58 \mathrm{E}-08$ & $1.43 \mathrm{E}-08$ & 1.000000000000000 & 3.03 & 0.254 & 0.0733 & 0.615 \\
\hline TCR3 & 3.1 & $1.70 \mathrm{E}-07$ & $4.29 \mathrm{E}-08$ & 0.999999999999996 & 2.81 & 0.26 & 0.0856 & 0.754 \\
\hline TCR4 & 3.7 & $7.50 \mathrm{E}-08$ & $1.70 \mathrm{E}-08$ & 1.000000000000000 & 3.53 & 0.253 & 0.0657 & 0.765 \\
\hline TCR5 & 3.77 & 8.73E-08 & $1.33 \mathrm{E}-08$ & 0.999999999999999 & 3.72 & 0.244 & 0.0604 & 0.748 \\
\hline TCR6 & 3.08 & $9.19 \mathrm{E}-08$ & $2.05 \mathrm{E}-08$ & 0.999999999999999 & 3.19 & 0.267 & 0.0705 & 0.693 \\
\hline TCR7 & 3.04 & $1.65 \mathrm{E}-07$ & $2.97 \mathrm{E}-08$ & 0.999999999999997 & 2.84 & 0.254 & 0.0811 & 0.785 \\
\hline TCS1 & 2.63 & $2.09 \mathrm{E}-07$ & $5.16 \mathrm{E}-08$ & 0.999999999999994 & 2.53 & 0.28 & 0.0921 & 0.772 \\
\hline TCS2 & 3.57 & $7.36 \mathrm{E}-08$ & $1.27 \mathrm{E}-08$ & 1.000000000000000 & 3.53 & 0.214 & 0.0503 & 0.833 \\
\hline TCS3 & 3.72 & $6.65 \mathrm{E}-08$ & $9.68 \mathrm{E}-09$ & 1.000000000000000 & 3.56 & 0.248 & 0.0605 & 0.768 \\
\hline TCS4 & 3.63 & $8.04 \mathrm{E}-08$ & $1.70 \mathrm{E}-08$ & 0.999999999999999 & 3.56 & 0.233 & 0.0486 & 0.842 \\
\hline TCS5 & 3.05 & $6.74 \mathrm{E}-08$ & $1.74 \mathrm{E}-08$ & 1.000000000000000 & 3.03 & 0.25 & 0.079 & 0.73 \\
\hline TCS6 & 4.59 & $4.79 \mathrm{E}-08$ & $7.51 \mathrm{E}-09$ & 1.000000000000000 & 4.56 & 0.255 & 0.0524 & 0.81 \\
\hline TCS7 & 2.89 & $1.42 \mathrm{E}-07$ & $3.29 \mathrm{E}-08$ & 0.999999999999997 & 2.78 & 0.281 & 0.0829 & 0.694 \\
\hline TCS8 & 2.75 & $1.38 \mathrm{E}-07$ & $4.16 \mathrm{E}-08$ & 0.999999999999998 & 2.81 & 0.269 & 0.0931 & 0.752 \\
\hline TCS9 & 2.4 & $1.03 \mathrm{E}-07$ & $4.14 \mathrm{E}-08$ & 0.999999999999998 & 2.38 & 0.155 & 0.0328 & 0.907 \\
\hline TE1 & 2.9 & $1.61 \mathrm{E}-07$ & 4.83E- 08 & 0.999999999999997 & 2.78 & 0.25 & 0.084 & 0.757 \\
\hline TE2 & 1.35 & $1.99 \mathrm{E}-07$ & $6.60 \mathrm{E}-08$ & 0.999999999999982 & 1.34 & 0.215 & 0.1304 & 0.855 \\
\hline TE3 & 2 & $1.77 \mathrm{E}-07$ & $6.00 \mathrm{E}-08$ & 0.999999999999993 & 1.97 & 0.216 & 0.0733 & 0.896 \\
\hline TE4 & 2.14 & $1.37 \mathrm{E}-07$ & $5.85 \mathrm{E}-08$ & 0.999999999999996 & 2.09 & 0.207 & 0.0812 & 0.858 \\
\hline TG1 & 1.5 & $2.04 \mathrm{E}-07$ & $6.61 \mathrm{E}-08$ & 0.999999999999985 & 1.56 & 0.23 & 0.155 & 0.844 \\
\hline TG10 & 2.21 & $1.13 \mathrm{E}-07$ & 5.83E- 08 & 0.999999999999997 & 2.16 & 0.195 & 0.0821 & 0.865 \\
\hline TG11 & 4.97 & $1.13 \mathrm{E}-08$ & $1.78 \mathrm{E}-09$ & 1.000000000000000 & 4.97 & 0.145 & 0.0163 & 0.367 \\
\hline TG2 & 3.31 & $2.00 \mathrm{E}-07$ & $4.46 \mathrm{E}-08$ & 0.999999999999997 & 3.28 & 0.241 & 0.0657 & 0.786 \\
\hline TG3 & 3.66 & $7.51 \mathrm{E}-08$ & $1.55 \mathrm{E}-08$ & 1.000000000000000 & 3.56 & 0.25 & 0.0664 & 0.77 \\
\hline TG4 & 3.25 & $5.94 \mathrm{E}-08$ & $1.58 \mathrm{E}-08$ & 1.000000000000000 & 3.06 & 0.26 & 0.0764 & 0.768 \\
\hline TG5 & 3.61 & $1.85 \mathrm{E}-07$ & 3.93E-08 & 0.999999999999997 & 3.53 & 0.259 & 0.0701 & 0.755 \\
\hline TG6 & 3.47 & $1.19 \mathrm{E}-07$ & $2.61 \mathrm{E}-08$ & 0.999999999999999 & 3.53 & 0.291 & 0.0787 & 0.767 \\
\hline TG7 & 3.31 & $7.49 \mathrm{E}-08$ & $1.50 \mathrm{E}-08$ & 0.999999999999999 & 3.28 & 0.255 & 0.0718 & 0.726 \\
\hline TG8 & 3.1 & $1.56 \mathrm{E}-07$ & $4.83 \mathrm{E}-08$ & 0.999999999999997 & 2.81 & 0.237 & 0.0687 & 0.594 \\
\hline TG9 & 3.86 & $2.50 \mathrm{E}-07$ & $3.44 \mathrm{E}-08$ & 0.999999999999995 & 3.72 & 0.257 & 0.0649 & 0.649 \\
\hline TL1 & 3.57 & $7.40 \mathrm{E}-08$ & $1.55 \mathrm{E}-08$ & 1.000000000000000 & 3.53 & 0.252 & 0.0662 & 0.769 \\
\hline TL2 & 2.34 & $1.06 \mathrm{E}-07$ & $4.38 \mathrm{E}-08$ & 0.999999999999998 & 2.31 & 0.16 & 0.0416 & 0.892 \\
\hline TL3 & 2.93 & $1.60 \mathrm{E}-07$ & $4.30 \mathrm{E}-08$ & 0.999999999999997 & 2.84 & 0.281 & 0.0829 & 0.742 \\
\hline TL4 & 3.2 & $1.72 \mathrm{E}-07$ & $4.30 \mathrm{E}-08$ & 0.999999999999997 & 2.91 & 0.275 & 0.0801 & 0.749 \\
\hline TM1 & 2.84 & $1.36 \mathrm{E}-07$ & $4.53 \mathrm{E}-08$ & 0.999999999999998 & 2.69 & 0.24 & 0.0649 & 0.777 \\
\hline TM2 & 2.46 & $1.03 \mathrm{E}-07$ & $3.99 \mathrm{E}-08$ & 0.999999999999998 & 2.47 & 0.281 & 0.0456 & 0.756 \\
\hline TM3 & 3.59 & $6.02 \mathrm{E}-08$ & $1.20 \mathrm{E}-08$ & 1.000000000000000 & 3.56 & 0.215 & 0.053 & 0.866 \\
\hline TM4 & 3.12 & $9.14 \mathrm{E}-08$ & $2.90 \mathrm{E}-08$ & 0.999999999999999 & 2.91 & 0.252 & 0.0768 & 0.63 \\
\hline TT1 & 3.65 & $7.25 \mathrm{E}-08$ & $1.20 \mathrm{E}-08$ & 1.000000000000000 & 3.56 & 0.255 & 0.0657 & 0.761 \\
\hline TT2 & 3.51 & $7.78 \mathrm{E}-08$ & $1.20 \mathrm{E}-08$ & 1.000000000000000 & 3.53 & 0.261 & 0.0717 & 0.753 \\
\hline
\end{tabular}




\section{Discussion of Findings}

This study employs ANFIS as an intelligent machine learning technique to predict the uncertainty events in the construction cost of highway projects and thereafter compares the prediction performance of ANFIS to the SRA as a classical statistical technique. The success or failure of prediction depends on the credibility and performance of the prediction technique. The comparison of calculated R-Values from ANFIS and SRA (Table 3) revealed that the Rvalue of intelligent machine learning method is significantly close to 1 , which means the predicted impact size of uncertainty events by ANFIS has a higher fitness to the real data. For Instance, the fitness of predicted impact size of event EC1 (fluctuation of prices) is improved from low fitness $(0.659)$ to perfect fitness similarly for all the events.

Also, it emerged that intelligent machine learning technique improves the reliability of prediction by reducing both error indicator scores. Table 3 shows the two minimal error values of ANFIS on predicted impact size (very close to 0 ). For Instance, the RMSE score of event EC1 is decreased from 0.213 to $6.05 \mathrm{E}-$ 08 similarly the MAPE score is reduced from 0.0484 to $1.35 \mathrm{E}-08$. Therefore, the minimal error indicator values and the extreme closeness of the R-Value to 1 for ANFIS technique manifests the higher credibility and accuracy of intelligent machine learning methods in predicting the impact size of uncertainty events when compared to the classical statistical method. Furthermore, the comparison of the predicted impact size of the uncertainty events from SRA and ANFIS techniques revealed that the SRA technique generally underestimated (62 out of 76) of the impact size of uncertainty events by an average of $-6.5 \%$.

\section{Conclusions}

This study examines the capabilities and credibility of ANFIS as an intelligence machine learning method for predicting the impact size of uncertainty events on construction cost of projects. The results show that intelligent machine learning method (ANFIS) is more accurate than the classical mathematical method (SRA) in both fitness and reliability of the prediction model. Also, the research results suggest that intelligence machine learning methods such as ANFIS could be used as a superior technique for predicting the impact of uncertainty in construction projects mainly when the input data are ambiguous or subject to relatively high uncertainty. The hybrid intelligent learning ability of Fuzzy Inference System (FIS) empower the ANFIS in learning, modelling and analysing the qualitative aspects of data such as human knowledge. The strength of the hybrid intelligent learning methodology provides a simple and efficient approach over other conventional methods of prediction such as classical statistical techniques including Regression Analysis. Besides accurate prediction and evaluation of uncertainty impacts, the ANFIS also reduces the potential inconsistency of correlations.

The study advances that the use of ANFIS technique could be extended to the management of uncertainties in various sectors of the construction industry. Also, that managing the uncertainties on projects could be executed more systematically using the advantages of the designed FIS and higher performance of predicted size by ANFIS. The use of a similar approach in evaluating the performance of intelligent machine learning methods as a predictor of various variables in the construction industry such as project complexity and project performance is recommended as the focus of further studies.

This study provides an accurate impact size of uncertainty events on the cost of highway construction projects as a baseline for future studies. By using this baseline and tailormade effect value for each impact size class it is possible to estimate the exact amount of construction cost of highway projects. In this study, the ANFIS was applied to assess the impact of uncertainty events on the cost of highway construction projects, due to its effectiveness in predicting, learning and modelling human knowledge. The strength of the proposed methodology provides a simple and efficient approach over other conventional methods of impact assessment which can be used by other researchers as a new research direction to explore the advantages and reliability of machine learning on other areas of construction management over the standard and classical methods.

\section{Acknowledgments}

The financial assistance of the National Research Foundation (NRF) towards this research is hereby acknowledged. The opinions expressed, and conclusions arrived at, are those of the authors and are not necessarily to be attributed to the NRF.

\section{References}

Antunes, R., \& Gonzalez, V. (2015). A production model for construction: A theoretical framework. Buildings, 5(1), 209-228.

Chai, Y., Jia, L., \& Zhang, Z. (2009). Mamdani model based adaptive neural fuzzy inference system and its application. International Journal of Computational Intelligence, 5(1), 22-29.

Chan, A. P., \& Chan, A. P. (2004). Key performance indicators for measuring construction success. Benchmarking: an international journal, 11(2), 203-221.

Chan, A. P., Ho, D. C., \& Tam, C. (2001). Design and build project success factors: multivariate analysis. Journal of Construction Engineering and Management, 127(2), 93-100. 
Creedy, G. D., Skitmore, M., \& Wong, J. K. (2010). Evaluation of risk factors leading to cost overrun in delivery of highway construction projects. Journal of Construction Engineering and Management, 136(5), 528-537.

Diab, M. F., Varma, A., \& Panthi, K. (2017). Modeling the Construction Risk Ratings to Estimate the Contingency in Highway Projects. Journal of Construction Engineering and Management, 143(8), 04017041.

Ebrat, M., \& Ghodsi, R. (2014). Construction project risk assessment by using adaptive-network-based fuzzy inference system: An empirical study. KSCE Journal of Civil Engineering, 18(5), 1213-1227.

El Khalek, H. A., Aziz, R. F., \& Kamel, H. M. (2016). Risk and Uncertainty Assessment Model in International Construction Projects Using Fuzzy Logic.

Fragiadakis, N., Tsoukalas, V., \& Papazoglou, V. (2014). An adaptive neuro-fuzzy inference system (anfis) model for assessing occupational risk in the shipbuilding industry. Safety Science, 63, 226-235.

GüNeri, A. F., Ertay, T., \& YüCel, A. (2011). An approach based on ANFIS input selection and modeling for supplier selection problem. Expert Systems with Applications, 38(12), 14907-14917.

ISO, I. (2009). 31000: 2009 Risk ManagementPrinciples and Guidelines. International Organization for Standardization, Geneva, Switzerland.

Jin, X.-H. (2010). Neurofuzzy decision support system for efficient risk allocation in public-private partnership infrastructure projects. Journal of computing in civil engineering, 24(6), 525-538.

Li, K., Su, H., \& Chu, J. (2011). Forecasting building energy consumption using neural networks and hybrid neuro-fuzzy system: A comparative study. Energy and Buildings, 43(10), 2893-2899.

Lughofer, E. (2011). Evolving fuzzy systemsmethodologies, advanced concepts and applications (Vol. 53): Springer.

Moghayedi, A., \& Windapo, A. (2018). Identification of the Uncertain Events Impacting On Construction Time of South African Highway Projects. Paper presented at the 10th cidb Postgraduate Conference, Port Elizabeth, South Africa.

Moore, D. S., \& Kirkland, S. (2007). The basic practice of statistics (Vol. 2): WH Freeman New York.
Negnevitsky, M. (2005). Artificial intelligence: a guide to intelligent systems: Pearson Education.

Ng, S. T., \& Zhang, Y. (2008). Optimizing construction time and cost using ant colony optimization approach. Journal of Construction Engineering and Management, 134(9), 721-728.

Ökmen, Ö., \& Öztaş, A. (2010). Construction cost analysis under uncertainty with correlated cost risk analysis model. Construction Management and Economics, 28(2), 203-212.

PMI. (2013). A Guide to the Project Management Body of Knowledge: PMBOK Guide: Project Management Institute.

Ramanathan, C., Narayanan, S., \& Idrus, A. B. (2012). Construction delays causing risks on time and costa critical review. Construction Economics and Building, 12(1), 37-57.

Shahhosseini, V., \& Sebt, M. (2011). Competencybased selection and assignment of human resources to construction projects. Scientia Iranica, 18(2), 163-180.

Sinesilassie, E. G., Tabish, S. Z. S., \& Jha, K. N. (2017). Critical factors affecting schedule performance: A case of Ethiopian public construction projects-engineers' perspective. Engineering, Construction and Architectural Management, 24(5), 757-773.

Skitmore, R. M., \& Ng, S. T. (2003). Forecast models for actual construction time and cost. Building and Environment, 38(8), 1075-1083.

Thomas, A., Kalidindi, S. N., \& Ananthanarayanan, K. (2003). Risk perception analysis of BOT road project participants in India. Construction Management and Economics, 21(4), 393-407.

Ugur, L. (2017). A Neuro-Adaptive Learning (NAL) Approach about Costs of Residential Buildings. Acta Physica Polonica A, 132(3), 585-587.

Veerasamy, R., Rajak, H., Jain, A., Sivadasan, S., Varghese, C. P., \& Agrawal, R. K. (2011). Validation of QSAR models-strategies and importance. International Journal of Drug Design \& Discovery, 3, 511-519.

Wang, Y.-M., \& Elhag, T. M. (2008). An adaptive neuro-fuzzy inference system for bridge risk assessment. Expert Systems with Applications, 34(4), 3099-3106.

Yun, S., Jung, W., Han, S. H., \& Park, H. (2015). Critical organizational success factors for public private partnership projects-a comparison of solicited and unsolicited proposals. Journal of Civil Engineering and Management, 21(2), 131-143. 